INVESTIGACIÓN

http://doi.org/10.15198/seeci.2019.49.141-158

Recibido 02/10/2018 --- Aceptado: 22/02/2019 --- Publicado: 15/07/2019

\title{
EL POPULISMO DE IZQUIERDAS EN EL DISCURSO DE PABLO IGLESIAS
}

\section{THE POPULISM OF LEFT IN THE SPEECH OF PABLO IGLESIAS}

Rafael Barberá González: Universidad Complutense de Madrid. España. rbarbera@ucm.es

Félix Martín del Fresno: Universidad Complutense de Madrid. España. felixmartindf@gmail.com

\section{RESUMEN}

Durante los últimos años y de manera creciente, se han originado movimientos populares en numerosos países del mundo. Una de las razones puede ser, entre otras muchas, que la sociedad percibe que recibe de sus líderes una gestión deficiente y poco ética. Ante este auge que ha tenido un notable eco en el continente europeo, el presente trabajo busca averiguar si líderes políticos, como por ejemplo, Pablo Iglesias, en el caso español, han utilizado el populismo como estrategia discursiva para conseguir votos. Se analizarán las características del populismo denominado de derechas y el denominado de izquierdas, para valorar si hay diferencias sustanciales entre ambos. Además, se mencionará el sistema en el que mejor se desenvuelve el populismo, la democracia, aunque no exista un consenso entre los autores que creen que se da en otros entornos. Por último, se realizará una referencia a la evolución del populismo en España para, a seguido, analizar algunos de los discursos de Pablo Iglesias.

PALABRAS CLAVE: Democracia - España - populismo - Pablo Iglesias - discurso votos.

\section{ABSTRACT}

During recent years and increasingly, popular movements have originated in many countries around the world. One of the reasons may be, among many others, that society perceives that it receives poor and unethical management from its leaders. Given this boom that has had a remarkable echo in the European content, this paper seeks to find out if political leaders, such as Pablo Iglesias, in the Spanish case, have

${ }^{1}$ Rafael Barberá González: Doctor en Periodismo por la Universidad San Pablo-CEU, licenciado en Periodismo por esta Universidad y licenciado en Derecho por la UCM. Profesor en la Facultad de Ciencias de la Información de la UCM y en la Facultad de Comunicación de la UFV.

rbarbera@ucm.es 
used populism as a discursive strategy to get votes. The characteristics of the socalled right-wing populism and the so-called left-wing populism will be analyzed to assess whether there are substantial differences between the two. In addition, we will mention the system in which populism best develops, democracy, although there is no consensus among authors who believe that it occurs in other environments. Finally, a reference to the evolution of populism in Spain will be made, followed by an analysis of some of Pablo Iglesias' discourses.

KEY WORDS: Democracy - Spain - populism - Pablo Iglesias - speech - votes.

\section{O POPULISMO DE ESQUERDA NO DISCURSO DE PABLO IGLESIAS}

\section{RESUME}

Durante os últimos anos e de maneira crescente, originaram-se movimentos populares em numerosos países do mundo. Uma das razoes poder ser, entre várias, que a sociedade percebe que recebe de seus líderes uma gestão deficiente e pouco ética. Diante deste auge, que teve um eco notável no continente europeu, o presente trabalho busca averiguar se líderes políticos, como por exemplo, Paulo Iglesias na Espanha, utilizaram o populismo como estratégia discursiva par conseguir votos. Analisaram-se as características do populismo denominado de direita e o de esquerda, para avaliar se tem diferenças substanciais entre ambos. Ademais, se mencionara o sistema no qual melhor se desenvolve o populismo, a democracia, mesmo que não exista um consenso entre os autores que creem que acontece em outros entornos. Por último, se realizará uma referência a evolução do populismo na Espanha e em seguida, analisar alguns discursos de Pablo Iglesias.

PALAVRAS CHAVE: Democracia - Espanha - populismo - Pablo Iglesias - discurso - votos.

\section{Cómo citar el artículo:}

Barberá González, R., y Martín del Fresno, F. (2019). El populismo de izquierdas en el discurso de Pablo Iglesias. [The populism of left in the speech of Pablo Iglesias]. Revista de Comunicación de la SEECI, 49, 141-158. doi: http://doi.org/10.15198/seeci.2019.49.141-158

Recuperado de http://www.seeci.net/revista/index.php/seeci/article/view/558

\section{INTRODUCCIÓN}

Muchos autores como Ernesto Laclau, Francisco Panizza, Michael Connif, entre otros, han estudiado casos de populismo que se han producido a lo largo de la historia. Fue en el siglo XX cuando se produjo la denominada "época dorada" del populismo, sobre todo en América Latina, con los gobiernos de Juan Domingo Perón en Argentina, Alberto Fujimori en Perú, Getúlio Vargas en Brasil o, incluso, el intento de alcanzar la Casa Blanca de George Wallace. 
En el populismo se produce una construcción política antagónica que se forma a través de un proceso de nominación ("nosotros" y "ellos"). Además, se necesitan antes unas condiciones específicas para que "emerja la semilla". Esta principal condición que conduce a una práctica populista es la situación donde coexisten una pluralidad de demandas que el sistema institucional es incapaz de absorber.

Algunos escenarios de surgimiento del populismo pueden ser una ruptura del orden social y la pérdida de confianza en la capacidad del sistema político para restaurarlo, el agotamiento de las tradiciones políticas y el desprestigio de los partidos políticos o cambios a nivel económico, cultural y social.

\section{OBJETIVOS}

El principal objetivo de este trabajo es comprobar si Pablo Iglesias utilizó en sus discursos el populismo con la idea, entre otras, de conseguir los votos de los ciudadanos.

Además, se busca averiguar qué técnicas propias del populismo de izquierda utiliza en sus discursos, especialmente en período electoral.

\section{METODOLOGÍA}

Este artículo realiza un análisis de contenido de los discursos de Pablo Iglesias. El análisis de contenido "es una técnica de investigación para formular inferencias identificando de manera sistemática y objetiva ciertas características específicas dentro de un texto" (Holsti, 1969). Y el análisis de discurso "hace referencia al acto conversacional y a los procesos estructurales de interacción que en él se producen" (Andréu Abela, 2001).

El objeto de estudio es el discurso de Pablo Iglesias y, en este caso, se han elegido dos: el último de la campaña de las elecciones del 26 de junio de 2016, pronunciado el 24 de ese mes, y el primero tras los comicios, el mismo día 26.

Para codificar estos discursos se tendrán en cuenta algunos de los elementos planteados por Van Dijk (1996):

1. Tipo de discurso

2. Estilo

3. Léxico

4. Sintaxis

5. Fonología

\section{DISCUSIóN}

\subsection{El populismo de derechas y de izquierdas}

En los últimos años, el populismo de derechas ha emergido en numerosos países de Europa, situándose en el centro de atención de todas las democracias 
occidentales. Partidos como el Frente Nacional de Jean Marie Le Pen en Francia o el Partido por la libertad de Geert Wilders en los Países Bajos, son percibidos como las principales amenazas a las instituciones democráticas. En este sentido, Chantal Mouffe, profesora de Teoría Política, propone que el populismo de derechas es el resultado del consenso pospolítico, es decir, de una "falta de un debate democrático efectivo sobre posibles alternativas, lo que ha conducido en muchos países al triunfo de partidos políticos que afirman ser la "voz del pueblo" (Mouffe, 2009).

Los partidos tradicionales no han sabido enfrentarse a los problemas sociales de un modo político ni presentar un equivalente a un discurso de Responsabilidad social mediática en la línea de lo expuesto por Viñarás Abad (2010). Esto es por lo que se entiende que el poder jurídico (o legal) haya adoptado el ámbito en el que los conflictos sociales puedan encontrar una forma de expresión, según Mouffe. Este cambio de lo político a lo legal para resolver las relaciones sociales tiene consecuencias negativas para la democracia. Es necesario buscar soluciones imparciales a los inconvenientes, pero este es el problema, que en la política no existen imparciales.

Según la misma autora, es esta incapacidad de los partidos otra de las condiciones de surgimiento de los partidos de derecha, los cuales son los únicos capaces de movilizar y crear identidades colectivas.

Como afirma Howard Gardner "el líder que triunfará es aquel que mejor perciba y exprese lo que el público ya desea" (Gardner, 1998). El pueblo se identifica con el líder por las historias que cuenta a través del empleo no solo de símbolos, sino también de su propio cuerpo y vida privada.

Por lo tanto, en un contexto en el que no existan alternativas efectivas ofrecidas a los ciudadanos, éstos cada vez más se dejarán persuadir por aquellos que afirman que las alternativas existen y que devolverán el poder al pueblo.

En política, siempre se encuentra la distinción entre el "nosotros" y el "ellos". Según Mouffe, este último está definido como "la extrema derecha", caracterizada por grupos heterogéneos como extremistas, neonazis, etc. Por tanto, el "nosotros" estará definido por los "buenos demócratas" los cuales poseen la verdad y su objetivo es establecerla frente aquellos que no son partidarios.

El populismo de izquierdas es más característico en los países latinoamericanos, sobre todo en la Argentina de Juan Domingo Perón, en el Brasil de Getúlio Vargas, el Perú de Alberto Fujimori o la Venezuela de Hugo Chávez, entre otros. Estos se caracterizan por un fuerte nacionalismo, programas económicos basados en subsidios, protección de la industria local, movilización contra la oligarquía, incorporación de las clases bajas, la creación de partidos políticos de masas, el culto a la personalidad que exalta la importancia del líder, etc. (Arditi, 2009). 


\subsection{El populismo como "síntoma" de la democracia}

Benjamín Arditi trata de analizar el concepto de populismo desde una perspectiva periférica interna de la política democrática, es decir, que el populismo actúa como espejo que muestra las partes desagradables de la democracia. El autor parte de una amalgama de conceptos de otros autores sobre el populismo, como Germani (1965), que lo interpreta como un extravío en el camino que hay desde una sociedad tradicional a una moderna, o Di Tella (1965), que lo concibe como la consecuencia de la confluencia de dos fuerzas antagónicas al poder (que son las masas populares y la élite educada pero empobrecidas) que buscan alternativas al mismo.

Es lógico que desde el otro bando de lo político califiquen el populismo como algo negativo. Sin embargo, otros se muestran distantes a la hora de rechazar los objetivos declarados como populistas ya que exponen políticas presentes en la agenda socialista y democrática radical, como el bienestar social y el empleo, etc., de acuerdo con Arditi. Esto hace entender que intelectuales de la época vean en el populismo algo positivo. Todo ello agravado por la insuficiente educación mediática apuntada por Marta-Lazo, Grandío Pérez y Gabelas Barroso (2013).

\subsection{El populismo en España y el perfil de Pablo Iglesias}

\subsubsection{Los orígenes del populismo español}

El populismo en España ha tenido pocas oportunidades para emerger, ya que durante aproximadamente un tercio del siglo pasado se desarrolló la dictadura franquista. Sin embargo, unos años antes a la dictadura se encuentra un caso de populismo. José Álvarez Junco, en su obra El emperador del paralelo: Lerroux y la demagogia populista, ofrece un retrato del que fue presidente del consejo de ministros de la Segunda República española, a quien el autor lo define como "el caudillo de las masas". Pero sin remontarnos varias décadas atrás, en la historia reciente de España se hallan figuras populistas que no llegaron a triunfar, como Jesús Gil y Gil, José María Ruiz Mateos o Mario Conde. Los tres se declararon críticos con "el sistema", lo que ahora se conoce como "casta" (Riaño, 2016). Estos trataron de trasladar su éxito en los negocios a la política, pero fracasaron en el intento. El último caso de populismo es el que se origina con el movimiento $15-\mathrm{M}$, que se encumbró con la creación del partido político de Podemos, con un carácter de populismo de izquierdas, algo que será muy criticado durante los próximos años por la oposición y por sus relaciones con Venezuela.

\subsubsection{España y Pablo Iglesias}

En 2008, era el socialista José Luis Rodríguez Zapatero quien gobernaba el país y quien tenía que hacer frente a una de las peores crisis de la historia. La economía nacional se iba deteriorando con el tiempo, el número de desempleados no paraba de crecer hasta alcanzar el máximo histórico de 5,3 millones de parados (Bolaños, 2012), se aumentó la edad de jubilación, se incrementó el Impuesto sobre el Valor Añadido (IVA), etc. Todos estos problemas desencadenaron en una protesta popular 
masiva por toda España a partir del 15 de mayo de 2011, lo que se denominaría como el Movimiento 15-M. Este movimiento social, surgido de la indignación popular, tenía como fin cambiar la política española, no se sentían representados por la actual clase política. Los numerosos casos de corrupción, el desempleo, los recortes y un sistema que no funcionaba al servicio de la sociedad provocó la mayor protesta producida en la Puerta del Sol, en Madrid, con el lema iDemocracia real ya! No somos mercancía en manos de políticos y banqueros.

Este movimiento, organizado a través de asambleas ciudadanas, se definía como apartidista y asindicalista que velaba por una democracia real y poder participar en las decisiones políticas, por lo que permanecieron acampados durante 28 días en forma de protesta en la Puerta del Sol. Entre las propuestas que demandaban: cambios en la Ley Electoral, desvinculación verdadera entre la Iglesia y el Estado, una reforma fiscal que favorezca a las clases bajas, transparencia de los partidos políticos, abolición de los sueldos vitalicios de los políticos, etc. (Blas, 2012).

Pablo Iglesias fue uno de los principales abanderados del movimiento, del cual afirmó que fue "la mejor expresión social de esa crisis del régimen político español" y que Podemos es su "mejor expresión política". Podemos fue fundado en 2014 a raíz de estos movimientos ciudadanos con el fin de buscar la mayor representación del pueblo y promover una renovación democrática. Todo comenzó con la firma del manifiesto Mover ficha: convertir la indignación en cambio político (Sánchez \& Gil, 2014) en el que se manifestaba la candidatura a las elecciones europeas liderados por Pablo Iglesias. Formados por una asamblea ciudadana, elaboraron su programa a través de una consulta de propuestas, en las que se contemplaban la disminución del salario mínimo, la defensa de los referéndums o la eliminación de la corrupción.

En las elecciones europeas obtuvieron cinco escaños, superando el millón de votos, y se posicionaron como la cuarta fuerza política. En el siguiente año, como antecedente a las elecciones generales que se celebrarían el 20 de diciembre, llegaron los comicios municipales y autonómicos. Aunque los sondeos indicaban que Podemos llegaba a superar al PSOE, finalmente se quedó como tercera fuerza en la mayoría de las autonomías. Esta posición se afianzaría con la celebración de las elecciones generales 20-D.

Pablo Iglesias, nacido en Madrid el 17 de octubre de 1978, es licenciado en Derecho y Ciencias Políticas por la Universidad Complutense de Madrid. En 2008 obtuvo el doctorado con una tesis sobre la acción colectiva postnacional. Profesor titular interino de Ciencias Políticas en la Facultad de Ciencias Políticas y Sociología (UCM) desde 2008 a 2013. Según aparece en el portal de transparencia de Podemos, en 2010 comenzó a dirigir y presentar La Tuerka en Tele K. En enero de 2013, comenzó a presentar Fort Apache, programa realizado por Producciones CMI, y en abril de ese mismo año comenzó su participación en debates y tertulias de diferentes medios de comunicación: La Sexta Noche (laSexta), Las mañanas de Cuatro (Cuatro), Te vas a enterar (Cuatro) y La noche en 24 horas (24 horas). Es fundador y Secretario General de Podemos. 
El líder de Unidos Podemos se caracteriza por dominar una gran oratoria. Según Luis Arroyo, sociólogo y consultor de comunicación política, respecto a Iglesias y al partido, "han diseñado un producto de marketing: un partido de izquierdas con un relato muy sencillo, que es el pueblo contra la casta. Son gente muy inteligente" (Machuca, 2014).

\subsubsection{Discurso de Pablo Iglesias}

Se han elegido para este trabajo dos discursos de Pablo Iglesias. El último pronunciado antes de las elecciones del 26 de junio de 2016 y el primero después de haberse celebrado dichos comicios.

El primero de ellos, en Madrid, estaba dirigido a sus simpatizantes y al pueblo español. Es un discurso cargado con un fuerte patriotismo y pertenencia de grupo, se citan constantemente las palabras "patria", "compatriota" y "España". Se observa la abundancia del uso de posesivos, en concreto de "nuestro" ("nuestra patria", "nuestro pueblo", "nuestro ADN") y de la primera persona del plural para formar y compartir la identidad del partido ("podemos", "estamos", "somos", "sabemos"), de la segunda persona del plural para hablar de los éxitos conseguidos hasta el momento ("sois la prueba", "sois el aval", "sois el ejemplo") y, por otro lado, el empleo del posesivo "su" ("su dinero"), y de la tercera del plural para hablar de aquellos que son el enemigo, el Partido Popular ("ellos", "no nos representan", "ganarles") y Europa ("élites alemanas"). Asimismo, se emplea para hablar de quienes no están o de las luchas sociales que se han llevado a cabo a lo largo de la historia ("está", "hubiera querido", "son"). Respecto a la segunda persona del plural, Pablo Iglesias la utiliza para encumbrar al pueblo por los movimientos sociales que han hecho posible el cambio, elevando así su importancia más allá del partido. Reserva el pronombre "ustedes" para elevar el registro y diferenciarse de aquellos por los que no se sienten representados.

En cuanto a la palabra "historia", Iglesias utiliza a lo largo de su discurso hechos históricos de las luchas sociales llevadas a cabo por el pueblo y los logros conseguidos por España, algo por los que se sienten orgullosos y con los que intenta tener un cierto grado pedagógico:

Hoy quiero pronunciar esa palabra: España, y decir que estoy orgulloso de esa España que inventó la palabra "liberal", orgulloso de esa España que expulsó a las tropas de Napoleón, orgulloso de los militares progresistas como Riego y Torrijos, (...) orgulloso de esa clase obrera que defendió los derechos sociales y el sufragio (Iglesias, 2016).

Del mismo modo, destaca la repetición de "corrupción", a la que hace referencia como "manzanas podridas", con la que hace ver que todos los problemas del país son a causa del comportamiento impropio de los políticos gobernantes a través de la estructura sintáctica "la corrupción es". Asimismo, Iglesias también se ayuda de la corrupción para presentar algunas de sus propuestas con la estructura "sabemos que 
la corrupción se combate". De esta forma, Iglesias se autoproclama el poder de la verdad y del único voto válido para derrotar al Partido Popular.

Asimismo, el uso de un lenguaje informal se desarrolla en otros momentos cuando pronuncia palabras como "tatuado", "se ha ido de rositas" o "viejo topo revolucionario". Por otro lado, se aprecian neologismos como "burbuja inmobiliaria" o "pelotazos urbanísticos" y expresiones abstractas como "viento del pueblo", "sopla ese excedente democrático" o "nueva gramática política".

Como es habitual, se emplean términos de matiz negativo para valorar la actual situación del país ("pobreza", "riesgo", "desempleo", "paro", "ladrones", "periferia", "prostituyen", "antisistema", "radicales", "extremistas"). Sin embargo, los positivos se emplean para agradecer al pueblo español y a sus compañeros de partido el éxito conseguido ("humilde", "gracias", "libertad", "dignidad", "sonrisas"). Destaca la utilización frecuente del plural masculino y femenino, resaltando así este último ("vosotros y vosotras", "abuelos y abuelas", "nietos y nietas").

Finalmente, en los aspectos fonológicos, Iglesias destaca por tener un tono desafiante y enfadado durante todo el discurso, excepto en el momento que cuenta una anécdota sobre un niño, Iglesias adquiere una tonalidad suave y emocional. Por otro lado, mantiene una cadencia normal y pausada con el fin de dar pie al aplauso del público.

El segundo discurso seleccionado fue pronunciado inmediatamente después de que se conocieran los resultados electorales del 26 de junio de 2016. Lo hizo delante de sus simpatizantes. En la misma línea que el anterior, Iglesias emplea de nuevo la primera persona del plural y el pronombre "nos" y "nosotros" y el posesivo "nuestro" para fortalecer ese sentimiento de pertenencia de grupo contra una élite, representada por términos como "los poderosos", "los arrogantes" o el pronombre "les". Asimismo, se repite de nuevo el uso de la segunda persona del plural para dirigirse a sus votantes: "miraros", "¿sabéis?", "tendríais", "seáis". Llama la atención en el inicio del discurso el empleo de la personificación como figura retórica, pero en este caso a la inversa: "Yo quiero que seáis leonas defendiendo a su camada".

Predomina el uso del término "gente" para hablar del pueblo español, que va acompañado de adjetivos como "humilde", "modesta" y "decente". Destaca también el uso de la expresión "las puertas del cielo" para referirse a la victoria de unas elecciones, un objetivo que desea constantemente: "porque no nacimos para resistir, nacimos para ganar, nacimos para vencer y con la dignidad de la gente, vamos a ganar".

Por último, los aspectos fonológicos son similares al anterior discurso. A pesar de haber perdido las elecciones, Iglesias no rebaja el tono y mantiene esa alta entonación con matices desafiantes que viene pronunciando anteriormente. 


\subsubsection{Interpretación del discurso de Pablo Iglesias}

Como se ha visto, en ambos discursos de Pablo Iglesias se observan claramente unos tintes de carácter populista. En España se estaba viviendo un momento en el que el futuro de país estaba en juego y, además, era una época en el que el espectro político era más amplio que nunca. Había una clara desconfianza por parte de la población hacia las instituciones públicas para restaurar la situación del país, un escenario que se mermaba aún más con la corrupción de los partidos. Por tanto, se tenían los ingredientes necesarios para un surgimiento populista, el cual se inició ya con el movimiento 15-M y con la fundación de Podemos.

El discurso se aúpa sobre la realidad de una crisis de daños por producto debido a errores humanos en la escala de García Ponce y Smolak-Lozano (2013) donde el producto es la gestión pública y los errores humanos la incompetencia de los gestores. En los discursos analizados, Iglesias logra formar un sujeto popular unido frente a un enemigo común ("los poderosos", "la élite", "los millonarios"), que en este caso es el partido liderado por Mariano Rajoy, formándose así una frontera social. Esta frontera fue creada debido a la insatisfacción de las demandas que el pueblo tenía ("desempleo", "corrupción", "pobreza", "bajos salarios", etc.) y que un líder, en este caso Pablo Iglesias, las fue reuniendo de una forma igual a pesar de que son completamente heterogéneas. Así, abunda en sus discursos el empleo de la primera persona del plural y de posesivos como "nuestro" para crear sentimiento gregario y compartir las ideas del partido. Podemos se apropia del poder de representación de "la gente" y del pueblo contra una élite política ajena. Asimismo, se emplea la segunda persona del plural para ensalzar al pueblo como los verdaderos causantes del cambio y, a su vez, llamar a la acción social.

Otros elementos populistas en los discursos de Iglesias son las constantes referencias históricas por las que se sienten orgullosos y representados, elevando así un acento didáctico. Esas luchas sociales que realizaron "nuestros abuelos y abuelas" son las que pretende Iglesias trasladar a su gente. Destaca también la aparición de nombres de poetas e intelectuales como Miguel Hernández, Rafael Alberti o Antonio Machado y de políticos como Salvador Allende, "un socialista de verdad". Esto se debe a que Iglesias utiliza parte de sus obras para enfatizar sus argumentos ("estamos aquí como decía Miguel Hernández para ser viento del pueblo") o para seguir ejemplos de políticos como Allende ("un socialista que ganó la cuarta vez que se presentó a las elecciones y aquí estamos para hacerlo cuantas veces sea necesario").

Iglesias también predica ser la fuerza política de la ley y el orden, reforzado con un sentimiento patriótico constante, ya que pronuncia en numerosas ocasiones "nuestra patria", "compatriotas", "orgulloso de esa España". Sin embargo, en este caso predomina una tendencia claramente de izquierdas y antielitista representados con las ideas del 15-M ("no nos representan"). Además, se hace referencia a un estado en el que la soberanía popular se ha perdido, que "ha dejado tirado" su gente, y por ello el intento de recuperarlo a través del orden y de la ley. 
Otra de las características del populismo que se halla en Pablo Iglesias es la capacidad de atribuirse verdades y de conocer la realidad del pueblo. De esta forma, se adquiere un cierto grado de empatía por aquellos que sufren las incompetencias del gobierno, así por ejemplo está la anécdota que cuenta sobre un niño de etnia gitana. Esto es otro de los elementos de un líder populista, contar historias con las que el pueblo se pueda sentir identificado.

Abundan términos y expresiones abstractas como "héroes", "rompeolas de la solidaridad internacional", "tinta de sangre de los pueblos", "la sonrisa de un país", los cuales tienen poca concreción y, por tanto, un ideal político vacío que dibujan una esperanza ilusoria al pueblo. Asimismo, se aleja de un lenguaje técnico con el fin de evitar ser una figura culta o lejana al pueblo; es por ello, que se encuentran expresiones como "se han ido de rositas", "sinvergüenzas", "cortijo particular".

\section{CONCLUSIONES}

El objetivo de la presente investigación era saber si el líder de la fuerza política de Unidos Podemos, Pablo Iglesias, articuló en sus discursos el populismo como modo de persuasión para conseguir votos en los comicios respectivos.

Pablo Iglesias sí empleó el populismo en sus discursos. Como hemos visto en los resultados, esta conjetura se cumple favorablemente ya que se encuentran en sus discursos elementos que caracterizan al populismo.

Iglesias y su partido atribuyen los problemas del país tanto a las élites tanto nacionales como internacionales (Europa) y apuestan por una política más progresista y de izquierdas centrada en la recuperación de los derechos del pueblo.

En la figura de Pablo Iglesias, se observa un populismo de izquierdas, característico de países de América Latina, en los que predominan un discurso paternalista, personalista, e incluso, carismático, que implican tanto a las clases urbanas como a sectores de la clase media.

En los discursos analizados se encuentran elementos característicos del populismo, gracias a un eficaz un empleo del lenguaje que ha sabido segregar en dos grupos claramente diferenciados y atribuir al partido la legitimidad de ser la voz del pueblo y ser el responsable de restaurar el país.

Asimismo, el estilo de Pablo Iglesias a la hora de pronunciar sus discursos es de un carácter desafiante y de enfado, en el que predomina un lenguaje más informal y coloquial, con una entonación claramente superior.

\section{REFERENCIAS}

Agencia EFE (2015). Pablo Iglesias reivindica a Podemos como el "movimiento heredero" del 15-M. Recuperado de http://www.eldiario.es/politica/Pablo-Iglesiasreivindica-Podemos-movimiento_0_388111803.html 
Andréu Abela, J. (2000). Las técnicas del análisis de contenido: una revisión actualizada. Universidad de Granada: Fundación Centro de Estudios Andaluces.

Arditi, B. (2009). "El populismo como periferia interna de la política democrática". En Panizza F., El populismo como espejo de la democracia (pp. 97-132). Buenos Aires, Argentina: Fondo de Cultura Económica.

Blas, E. G. (2012). Las 14.700 propuestas de cambio del 15-M. Recuperado de: https://politica.elpais.com/politica/2012/05/10/actualidad/1336649244_037483.ht $\mathrm{ml}$.

Bolaños, A. (2012). El paro sube a un máximo histórico con 5,3 millones de desempleados. Recuperado de https://economia.elpais.com/economia/2012/01/27/actualidad/1327653180_8502 15.html

Di Tella, T. (1965). Populismo y Reforma en América Latina, en Desarrollo Económico, volumen 4(16), 391-425.

Gardner, H. (1998). Mentes líderes. Una anatomía del liderazgo. Barcelona, España: Paidós.

Germani, G. (1965). Política y sociedad en una época de transición. Buenos Aires, Argentina: Paidós.

Holsti, O. R. (1969). Content analysis for the social sciences and humanities. Addison-Wesley.

Iglesias, P. (2016). Podemos. Recuperado de https://transparencia.podemos.info/perfil/estatal/pablo-iglesias-turrion

Machuca, P. (2014). Pablo Iglesias: virtudes y defectos del nuevo secretario general de Podemos. Recuperado de http://www.huffingtonpost.es/2014/11/16/pabloiglesias-podemos_n_6160082.html

Marta-Lazo, C., Grandío Pérez, M. M. y Gabelas Barroso, J. A. (2013). La educación mediática en las titulaciones de educación y comunicación de las Universidades españolas. Análisis de los recursos recomendados en las guías docentes. Revista de Comunicación Vivat Academia, XVII(126), 63-78. doi: http://dx.doi.org/10.15178/va.2014.126.63-78

Mouffe, C. (2009). El "fin de la política" y el desafío del populismo de derecha, en Panizza, F., El populismo como espejo de la democracia (pp. 71-96). Buenos Aires, Argentina: Fondo de Cultura Económica. 
Riaño, P. H. (2016). El día que España dijo: "populismo". El Español. Recuperado de http://www.elespanol.com/cultura/libros/20161230/182232347_0.html

Sánchez, J. L., \& Gil, A. (2014). Pablo Iglesias prepara su candidatura a las europeas: "Me han pedido que dé el paso". Recuperado de http://www.eldiario.es/politica/Pablo-Iglesias-Juan-Carlos-Monedero-candidatoeuropeas-podemos_0_216278861.html

Van Dijk, T. A. (1996). Análisis del discurso ideológico, en Versión, 6, 15-43.

Viñarás Abad, M. (2010). El discurso de la RSC en los medios de comunicación social. Revista de Comunicación Vivat Academia, XIII(110), 160-181. doi: http://dx.doi.org/10.15178/va.2010.110.160-181.

\section{ANEXOS}

\subsection{Discurso de Pablo Iglesias el 24 de junio de 2016}

"Muchas gracias, buenas noches Madrid.

Quiero pediros, en primer lugar, un aplauso cerrado para todos los militantes, para todos los voluntarios que han hecho posible esta campaña, compañeros y compañeras anónimas que se han dejado la piel para que el mensaje del cambio político llegue a todas partes. Un aplauso para los intérpretes de signos, que llevan la lengua de signos a las personas sordas. Muchas gracias compañeros.

Muchas gracias a las fuerzas políticas que han decidido caminar al encuentro de la historia, es un honor ser el candidato a la presidencia de fuerzas políticas como las mareas que soplan desde Galicia, como Compromis, moltes gràcies Mónica, como en Comù, como los compañeros de Mes y sobre todo como los compañeros de la izquierda histórica en Cataluña y en España. Muchas gracias Alberto Garzón, muchas gracias a Izquierda Unida, gracias al Partido Comunista por llevar este camino junto a nosotros y nosotras.

Esto no es una alianza electoral, esto es un compromiso con nuestra patria y con nuestro pueblo, estamos escribiendo la historia, estamos convirtiéndonos en un instrumento en manos de la gente y eso va más allá de cualquier alianza electoral y de cualquier acuerdo entre partidos. Estamos aquí para serviros, estamos aquí como decía Miguel Hernández para ser viento del pueblo. Muchas gracias pueblo, muchas gracias España por empujarnos.

Muchas gracias en tercer lugar a los ayuntamientos del cambio, vosotros y vosotras sois la prueba, sois el aval, de que no solamente podemos ganar elecciones, sino que podemos ganar mejor. Muchas gracias José Manuel Calvo por parar los pies a los especuladores. Gracias Madrid, gracias Barcelona, gracias Valencia, gracias 
Coruña, gracias Zaragoza. Sois el ejemplo, sois el mejor aval de que somos una fuerza política de gobierno capacitada para gestionar mejor que ellos.

$Y$, en cuarto lugar, muchas gracias a los que no están, a los militantes y a los luchadores ausentes, a los que se dejaron la piel en las cárceles, a los que se dejaron la piel en las huelgas, a los que son nuestros abuelos y abuelas, a los que son el orgullo de nuestra patria, en los tiempos de cambio histórico sopla ese excedente democrático de las luchas del pasado.

Me decían que hubiera querido estar en este acto con nosotros Marcos Ana, y que está enfermo y está en su casa, desde aquí le quiero decir que no solo es un referente de la izquierda, él es un héroe del pueblo, es un héroe de la patria, y estamos orgullos de tener tatuado en nuestro ADN las luchas sociales que empujaron los de atrás.

Quiero recordar esta noche a mis abuelos y abuelas socialistas, estamos aquí para honrar vuestro ejemplo, estamos aquí para estar a vuestra altura, estamos aquí para que nuestros nietos y nietas estén tan orgullosos de nosotros como nosotros lo estamos de nuestros abuelos.

Esto no es solamente, como decía antes, una alianza electoral, esto es un encuentro con la historia, estáis escribiendo la historia de España. Hoy quiero pronunciar esa palabra: España, y decir que estoy orgulloso de esa España que inventó la palabra "liberal", orgulloso de esa España que expulsó a las tropas de Napoleón, orgulloso de los militares progresista como Riego y Torrijos, orgulloso de los liberales y los demócratas españoles de la Gloriosa, orgulloso de Joaquín Costa y de la Institución Libre de Enseñanza, orgulloso de esa clase obrera que defendió los derechos sociales y el sufragio, orgulloso de esas mujeres que parió nuestra patria como la Nelken, como Dolores, como Montseni, como Victoria Kent, son nuestras madres, son nuestra matria y estamos orgullosos de esa España de poetas e intelectuales como Rafael Alberti, como Antonio Machado, como Miguel Hernández, orgulloso de los mineros asturianos, orgulloso de esa España que fue el rompeolas de la solidaridad internacional y de ese pueblo español que resistió como ningún pueblo de Europa al horror y al fascismo, estamos orgullosos de esa España.

Y en un día como hoy, en el que aquí hay banderas azules, quiero recordar el primer discurso que pude hacer en el Parlamento europeo, mirando a la cara a los diputados de la bancada de la extrema derecha y los euroescépticos, y les dije que el corazón de Europa es el antifascismo, y les recordé que los pilotos que comandaban los primeros tanques que entraron a París eran españoles, orgullosos de esos españoles de la división Leclerc, orgullosos de decir España, orgullosos de decir patria.

Orgullosos de esa España que luchó por sus libertades en la dictadura, orgullosos de una España diversa y plurinacional, que habla diferentes lenguas, que tiene diferentes culturas y diferentes sentimientos, nunca más una España que se imponga desde el centro y que no entienda la riqueza de una patria plurinacional. $Y$ orgulloso 
de esa España que aquel 15 de mayo de 2011 salió al encuentro con la historia, orgullosos del 15-M, el 15-M debería ser fiesta nacional en este país.

Estamos viviendo cambios históricos, y aquel 15-M significó que algo estaba cambiando en el subsuelo de la estructura social de nuestro país, no era nada fácil interpretar entonces aquel movimiento que con banderas diferentes, con banderas distintas que con otros lenguajes estaba construyendo la nueva gramática que serviría para el cambio político, dijo no nos representan y dijo queremos democracia, fueron muy pocos los que entendieron aquel mensaje y entre ellos mi homenaje hoy a Juan Carlos Monedero, que estuvo en las plazas desde el principio, muchas gracias Juan Carlos por su ejemplo.

Aquí el movimiento inauguró una nueva gramática política, nosotros hablamos de centralidad que no tiene nada que ver con el centro, la centralidad es esa tarea histórica del viejo topo revolucionario, consiste en entender las claves que permiten el cambio político en una sociedad, consiste en entender que la historia tiene momentos en los que se requiere de la concurrencia de gente muy distinta con ideas distintas, con orígenes distintos, con diferentes identidades y todos y todas la banderas, todos los colores son bienvenidos al cambio político y siguen siendo bienvenidos.

Quizá Podemos fue entonces la mejor traducción electoral de aquel movimiento, de aquel cambio en la estructura social de nuestro país, quiero dar las gracias a los primeros valientes que me acompañaron desde el inicio: a Miguel Urbán, a Jorge Moruno y a Tania por empujarme a dar el paso. Quiero dar las gracias a los que llegaron después, a Iñigo y su gente, a los compañeros de la Complutense, a Rafa e Irene Montero, y quiero dar las gracias especialmente a Pablo Echenique por señalar el camino correcto, es un honor compartir el futuro contigo, compañero. Y gracias a todos vosotros y vosotras, los militantes anónimos, los imprescindibles, los que sois los verdaderos protagonistas del cambio social.

Pero hoy quiero decir que hay algo mucho más importante que Podemos y es el encuentro histórico con la izquierda de toda la vida, la que mantuvo arriba las banderas de la dignidad en momentos muy difíciles, es un honor Alberto caminar a vuestro lado, es un honor que vayamos a construir el futuro juntos, es un honor que la tinta de las luchas sociales vaya a escribir el futuro de nuestro país.

Quiero dirigirme hoy a las personas que todavía no han decidido su voto y quiero ser muy claro como lo somos nosotros, sin ambigüedades, somos el voto útil para derrotar al Partido Popular, que todo el mundo lo tenga claro... y básicamente porque nosotros sí tenemos una propuesta de país.

Se ha hablado mucho de corrupción en esta campaña, a todo el mundo le parece mal la corrupción, pero no son solamente manzanas podridas, la corrupción no es solamente Mariano Rajoy, hay cínicos que pretenden blanquear al Partido Popular pintándolo de naranja y diciendo que sin Mariano Rajoy entonces se puede llegar a acuerdos. Lo digo muy claro desde aquí, el problema de la corrupción no es Mariano 
Rajoy solamente, el problema de la corrupción es que se ha convertido en el conjunto de dispositivos de aplicación del neoliberalismo en España, la corrupción son sinvergüenzas, la corrupción son ladrones, pero la corrupción es también un modelo que no funciona, la corrupción es el paro, la corrupción es que haya 2,7 millones de parados que no reciben ninguna prestación; la corrupción es un modelo político que permite que uno de cada tres compatriotas esté en riesgo de pobreza, la corrupción es la disminución de la población activa y poner en riesgo las pensiones, la corrupción se sostiene sobre modelo de pelotazos urbanísticos y burbujas inmobiliarias que destruyó la industria y el futuro de nuestro país, la corrupción no solamente son los sinvergüenzas, la corrupción es la forma de gobierno que lo que diga Berlín, las élites alemanas quisieron imponer a nuestra patria para que fuera una periferia, no somos una periferia de nadie, queremos ser un país a la altura del peso que nos corresponde.

Sabemos que la corrupción se combate con el código penal, sabemos que la corrupción se combate terminando con esa ley de enjuiciamiento criminal, reformada por el Partido Popular, lo que llamaron Ley Berlusconi, que impide investigar los casos de corrupción. Sabemos que la corrupción se combate con una ley de financiación de partidos que los equipare a las fundaciones y prohibiendo el endeudamiento bancario, porque quien tiene deudas con los bancos, gobierna o termina gobernando a favor de los bancos, pero además, pero además de eso, la corrupción se combate con un proyecto de país, la corrupción se combate reconociendo en los astilleros un sector energético, la corrupción se combate diciendo que en España hace falta un plan nacional de transición energética que sirva para rehabilitar edificios, para ahorrar energía y que sirva también para llevar a cabo una transición que haga nuestra patria independiente del petróleo, así se combate también la corrupción. La corrupción se combate con inspectores de Hacienda y con reformas fiscales para que esa minoría de privilegiados que se ha ido de rositas pague también impuestos. La corrupción también se combate derogando dos reformas laborales inútiles y defendiendo los derechos de los trabajadores y defendiendo el derecho a salarios dignos. La corrupción se combate no permitiendo que buena parte de nuestros compatriotas estén en riesgo de pobreza, por eso hace falta una renta. La corrupción se combate no solamente hablando de la violencia machista sino aplicando medidas, acabando con esa Ley Montoro que no permite a los ayuntamientos atender a las mujeres víctimas de violencia machista y aquí lo decimos alternativa habitacional para las mujeres víctimas de la violencia machista sin necesidad de denuncia. Corrupción es que haya bancos rescatados con dinero público que hayan podido desahuciar a familias, la corrupción se combate con dación en pago retroactiva y haciendo que el derecho a la vivienda sea de obligado cumplimiento para los poderes públicos.

Hoy hay un mensaje para todos los europeos y es un mensaje muy claro, la Europa de Alemania, la Europa de los recortes sociales, la Europa que humilla a los refugiados y no cumple los derechos humanos no sirve y no seduce lo que sedujo a las poblaciones europea para construir el proyecto de la unión era la garantía de los derechos sociales y los derechos humanos, no hay más identidad europea que esa el cumplimiento de los derechos humanos y la prosperidad asociada al estado del 
bienestar o recuperamos una idea de Europa asociada a los derechos sociales o se terminó Europa, por eso decimos que hay que democratizar Europa y que hay que señalar con el dedo a los responsables de las políticas de austeridad como lo que son, los enterradores del proyecto europeo.

Decimos que somos la fuerza política de la ley y el orden y lo decimos hoy, que hemos visto a policías mandados por el Ministerio de Interior, entrando sin orden judicial en la redacción de un periódico... ¿a quién hay que tener miedo? ¿A quién hay que tener miedo en este país? Han hablado de radicales y de extremistas y yo digo que los antisistema son los que prostituyen las instituciones poniéndolas a jugar en favor de los privilegiados.

Esta mañana ha habido una anécdota que contaba una compañera del ayuntamiento de Valencia que me ha conmovido y que me ha enseñado una vez más el significado de las instituciones y de la palabra patria, hablaba de unos niños de etnia gitana que por primera vez gracias al ayuntamiento iban al teatro a escuchar a Tomatito, cuando Tomatito termina de cantar, los niños se van y cuando Tomatito vuelve a salir, los niños se habían ido porque no sabían lo que era una bis, porque jamás habían podido ir a un concierto, eso es la patria que haya instituciones que permitan a los niños ir al teatro, que haya instituciones que permitan a los niños independientemente de su condición, tener escuelas, que haya instituciones que garanticen la salud y que garantice la dignidad de todo el mundo; por eso somos los institucionales, por eso somos los de la ley, porque la gente humilde solo tiene la ley y el derecho, y el derecho está escrito con las luchas sociales de los que nos precedieron, los millonarios no necesitan hospitales y escuelas públicas, se pueden pagar la privadas, los millonarios desprecian la ley, tienen su dinero en paraísos fiscales y en cuentas en Suiza, que no se atreva esa gente a pronunciar la palabra patria, a pronunciar la palabra España si los impuestos no los pagan aquí.

¿Qué es la patria? La patria es una bandera, bienvenidas todas las banderas, pero la patria son los hospitales, la patria son las escuelas, la patria es la ley de dependencia, la patria es ese estado que no deja tirado a su gente, es ese estado que se convierte en la expresión de la mayoría social y de la soberanía popular, por eso decimos hoy: patria, orden, ley, instituciones frente a los antisistema, frente a los que han fracaso, frente a los responsables de la crisis, frente a los responsables de que haya compatriotas que no puedan llegar a fin de mes ni llenar la nevera.

Y hay que decir cuál es el significado de nuestro proyecto político, hay que leer a Luis Alegre y a Carlos Fernández Liria, los mejores intérpretes de los clásicos, cuando dicen que el nuestro es el proyecto político de la Ilustración, defendemos la libertad, la igualdad, la fraternidad, el imperio de la ley, porque eso es lo que ha permitido los avances sociales, nunca más la palabra libertad manchada en los labios de los que privatizan, nunca más la palabra libertad para señalar que algunos se puedan llevar su dinero a Suiza o Andorra o Panamá, la palabra libertad es sagrada y está escrita con la tinta de sangre de los pueblos, la palabra libertad no se puede separar de la igualdad y de la fraternidad. Estamos orgullosos de ser hijos de las luchas sociales que nos trajeron las bases ideológicas de la modernidad y se los decimos a los 
antipatriotas que convirtieron las instituciones en su cortijo particular, decir hoy viva la patria es decir viva la libertad, viva la igualdad y viva la fraternidad. iAdelante, adelante que podemos, adelante que estamos muy cerca llenando con dignidad, con sonrisas y con orgullo las urnas del 26 de junio, adelante que podemos ganar, adelante la sonrisa de un país, adelante la gente humilde, adelante este pueblo, adelante España que podemos ganarles, que estamos muy cerca y como decía Salvador Allende, la historia es nuestra y la hacen los pueblos!

\subsection{Discurso de Pablo Iglesias el 26 de junio de 2016}

"Qué orgullo, qué orgullo miraros a la cara. Yo quiero que seáis leonas defendiendo a su camada, que sepan los poderosos que aquí nos tienen, que nosotros no nos vendemos, que les vamos a terminar ganando, que hace dos años en esta misma plaza, cuando algunos decían que habíamos tenido un éxito con 1,3 millones de votos, decimos que no era bastante, que queríamos ganar y aquí seguimos, llamando a las puertas del cielo, con gente humilde, con gente modesta, con la gente decente, muchas gracias.

Orgullosos de esa gente que se ha dejado la piel en la campaña, orgullosos de esa militancia, orgullosos de los compañeros de todas las organizaciones que hacen que cada vez seamos más empujando el cambio político. iMuchas gracias Alberto, muchas gracias Ada, muchas gracias Mónica! iEsto acaba de empezar!

Orgullosos de esta ciudad y de este país, orgullosos de los que nos precedieron, de los que levantaron las banderas de la libertad y de la dignidad, orgullosos de esta ciudad que fue el rompeolas de la lucha contra el fascismo, orgullosos de nuestro pasado. $Y$ orgullosos también de ese 15-M que señaló el camino, de ese 15-M que invitó a la transformación a muchos sectores sociales que son imprescindibles y que todavía tienen que incorporarse.

¿Sabéis? Hace 108 años nació Salvador Allende, un socialista de verdad, un socialista que es ejemplo para nosotros, un socialista que ganó la cuarta vez que se presentó a las elecciones y aquí estamos para hacerlo cuantas veces sea necesario, porque no nacimos para resistir, nacimos para ganar, nacimos para vencer y con la dignidad de la gente, vamos a ganar.

Tendríais, tendríais que miraros a la cara para ver cuánta dignidad y cuánto orgullo. iHoy hay que decirles, a los poderosos, a los arrogantes, hasta la victoria siempre!

\section{AUTORES:}

\section{Rafael Barberá González}

Doctor en Periodismo por la Universidad San Pablo-CEU, licenciado en Periodismo por esta Universidad y licenciado en Derecho por la UCM. Profesor en la Facultad de Ciencias de la Información de la UCM y en la Facultad de Comunicación de la UFV, 
donde dirige el Master Universitario en Producción y Realización en Radio y Televisión. Sus líneas de investigación se centran en la comunicación política y la comunicación de crisis. Ha publicado varios artículos científicos sobre estas materias. rbarbera@ucm.es

Orcid ID: https://orcid.org/0000-0001-7471-3992

\section{Félix Martín del Fresno}

Graduado en Periodismo por la Universidad Rey Juan Carlos y Magíster en Comunicación de las Organizaciones por la Universidad Complutense de Madrid.

felixmartindf@gmail.com 